\title{
Analysis of China's Energy Efficiency Evaluation in the Background of
}

\section{Low-Carbon}

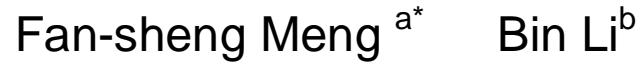 \\ School of Economics and Management Harbin Engineering University, HEU Harbin,China \\ axlt0803@126.com, ’bb70@sohu.com
}

\begin{abstract}
Keywords: Energy Efficiency Evaluation; China; Low-Carbon
Abstract: China is one of the world's largest energy consuming countries, energy performance evaluation is one of the issues of concern. This paper analyzes Chinese energy efficiency evaluation in the background of low-carbon including the review of the impact of energy efficiency on economic growth and the improvement of the energy efficiency of the whole society. It has the important guiding significance for the construction of China's energy-saving society.
\end{abstract}

\section{Introduction}

Energy is a significant material basis for human survival and development. Continued increase in global energy consumption and the high cost of new energy in high-tech make energy supply shortage occurs, which affects political, economic and social stability in a huge degree. Many researchers have studied the energy efficiency improvement and energy saving potential from different aspects, and they think that improvement of energy efficiency is an essential means to reduce energy intensity and alleviate structural contradictions. Chinese government proposed that the energy consumption per unit of GDP in the twelfth five-year plan should reduce about $20 \%$ comparing with the eleventh five-year plan. The government also pointed out that the transformation of economic development should mainly rely on advances in science and technology, but not rely heavily on consumption of resources.

From the vertical perspective, China's energy utilization efficiency shows the features of lower energy consumption intensity, lower energy consumption elasticity coefficient and higher energy economic efficiency. From 1978 to 2010, according to the 1978 comparable prices, China's energy consumption per GDP drops from 15.68 tons of standard coal in 1978 to 5.66 tons of standard coal in 2010 and the average energy consumption elasticity coefficient is 0.53 , maintaining high economic growth rate with lower elasticity of energy consumption. From the horizontal perspective, China's energy efficiency is much lower than that of the developed countries. Chinese specific energy consumption structure determines that the coal consumption in the total consumption of primary energy accounts for a high proportion, which in 2012, 2013 and 2014 are as high as 66.4\%, $65.7 \%$ and $64.2 \%$, resulting in high resources and energy consumption, low utilization and serious environmental pollution.

Developed countries start to pay attention to the energy resources after the energy crisis. The EU started early on ODDSAY plan to guide the EU's energy statistics in order to compare energy efficiency. Currently in cross-country comparisons, researchers usually use the microscopic or macroscopic energy intensity as the comparative index, but in theory, there has been lack of a more comprehensive theoretical methods and indicators. 


\section{Influence Factors of Energy Efficiency}

Researchers believe that influence factors of energy efficiency can be divided into two categories, one is the change of industrial structure and the other is the technological progress. Kambara (1992) thinks that the contribution rate of the industrial structure is max which accounts for $70 \%$ for the decrease of the energy intensity. Fisher-Vanden et al. (2004) considers that the changes in the industry structure is a major factor in reducing China's energy intensity and its contribution rate reaches $53 \%$ by studying Chinese medium-sized enterprises. Zhang (2003) works on the improvements of the energy efficiency of Chinese industrial sector from 1990 to 1997, and shows that the impact of the adjustment of industrial structure plays a negative role on the China's energy efficiency. Fisher-Vanden et al. (2004) uses panel econometric analysis methods to analyze China's energy intensity from 1997 to 1999 and find that increasing in R\&D expenditure, rising energy prices, and industrial structure adjustment are the main reasons which lead to the decrease of China's energy intensity during this period. Wing (2008) deeply analyzes the reasons which lead to the improvement of the American energy efficiency during 1958 and 2000 and shows that the main reason for the United States to reduce energy intensity is the change in the industrial structure. But after 1980, improving the energy efficiency of various industrial sectors plays a greater role on lowering the overall energy intensity in America. In addition to changes in the industrial structure, technological progress is also the main reason for the increase of energy efficiency. Studies find that increasing the amount of patents granted can reduce energy consumption, and the R\&D investments play a positive role on improving energy efficiency. Zheng et al (2003) shows that from 1980 to 1994 the decrease of energy intensity mainly caused by the technological progress. Chang and $\mathrm{Hu}$ (2010) detects that energy productivity decline in China is attributable to negative technical growth.

\section{Energy Efficiency Under Low-Carbon}

Low-carbon economy is to improve the efficiency of energy production and consumption and to reduce dependence on fossil fuels through technology, regulations, industrial structure and new energy development achieving economic and social development simultaneously. Boyd and Pang (2000) and Färe (2004) firstly utilize the Data Envelopment Analysis (DEA) for efficiency evaluation of energy and environment. Then Hu and Wang (2006) use the DEA method and first propose total factor energy efficiency (TFEE) concept based on total factor productivity framework. TFEE is defined as the ratio of the required energy input and the actual energy input under the optimal production efficiency when other factors except energy remain unchanged (Zhang and Wang, 2008; Mukherjee, 2008; Yeh et al., 2010). Hu and Wang (2006) first calculate the TFEE of Chinese provinces. Based on TFEE Hu and Kao (2007) further propose energy saving rate which is defined as the ratio of the energy savings and the actual energy input. Then they measure the actual energy saving rate of Shanghai Cooperation Organization members, show that China has the highest rate of energy saving. Decomposition of carbon emissions growth mainly use Index Decomposition Analysis (IDA) method and Structural Decomposition Analysis (SDA) method. Using IDA method, Fan et al. (2007) find that energy intensity was mainly driven by the change of primary energy-related carbon intensity and material sectors' final energy-related carbon intensity. Cao et al. (2010) analysis China's farming sectors from 1978 to 2004 by means of SDA. They found that China's energy-use efficiency has decreased in farming due to overuse of fossil energy inputs. The fact that changes in fossil energy use technology in farming since 1990 have provided negative help to rise of energy productivity in China' agro-ecosystem demonstrates the urgent need to improve the efficiency of fossil energy use and to seek alternatives to this energy source. Zhang (2009) use the 
SDA to analysis the sources of carbon intensity change in China. Their results show that the Chinese economy has displayed an obvious decarbonizing trend between 1992 and 2006, largely because of the transformation of their mode of economic development.

\section{Evaluation of Energy Efficiency}

For measurement of the energy efficiency, it needs to define the output function, but the energy itself has no output and it should be combined with other production factors in order to create the output. So the data envelopment analysis (DEA) could address these issues in measurement effectively (Afriat, 1972; Charnes and Cooper, 1978; Banker and Charnes, 1984). The data envelopment analysis method is used widely in the field of energy economics. Freeman et al. (1997), Boyd and Pang (2000) earlier discuss with DEA method to measure energy efficiency issues. Färe (2004) uses DEA to construct environmental pollution model that contains energy inputs calculation. Hu and Kao (2007) propose energy saving rate and use this method to measure the APEC countries between 1991 and 2000. Mukherjee (2008) calculate energy efficiency of manufacturing in India's 18 states, at the same time they use regression method to analyze the differences among state's energy efficiency. The results showed that the quality of human resources affect the energy efficiency positively. Many Chinese scholars also apply the DEA to analysis the energy efficiency. Bian and Yang (2010) proposed several DEA models to measure energy and environmental efficiency, and applied their models in the resource and environmental efficiency evaluation problem of 30 Chinese provinces. Shi et al. (2010) presented three extended DEA models that treated the undesirable outputs as inputs and made them decrease with energy inputs proportionally so as to calculate the energy and environmental overall technical efficiency, pure technical efficiency, and scale efficiency of 28 administrative regions in China.

\section{Energy Efficiency Improvement}

Cromption and $\mathrm{Wu}$ (2005) analysis China's energy consumption trend from 1953 to 2003 and use Bayesian regression model to predict the next seven years' energy demand in China. Yang (2008) discusses the possibility of reduction of the energy consumption per GDP in China's Eleventh Five-Year Plan (FYP) and gives the measures to realize the goal. China's Eleventh FYP set a goal of reducing energy intensity by $20 \%$ by 2010 . Price et al. (2011) assess the implement of the Eleventh FYP and select regulations and projects that government has carried out to achieve the goal, finding that most of the energy efficiency programs meet the saving targets. Currently in China, the appliance standards and the patent system become completed. The authorities have enhanced the energy standards for the buildings and tried to adjust the economic structure, however the achievement is not satisfied. Researchers think that it is significant to maintain and strengthen the existing energy-saving policies and programs that are successful while revising programs or adding new policy mechanisms to improve the programs that are not on track to achieve the stated goals (Kong et al., 2012).

\section{Conclusions}

As China transfers from the exporter to the net importer of energy, more and more Chinese scholars turn attention on China's energy efficiency research and more quantitative method is applied to researches. Researchers generally believe that China's energy consumption growth rate is far lower than the economic growth rate because of substantial increase in energy efficiency since the reform and opening-up. Factors affect energy efficiency can be divided into industrial structural 
changes, technological progress and the degree of economic opening. Most scholars utilize factorization or hierarchical regression method to obtaining the conclusions above, but the decomposition method takes into account limited factors and hierarchical regression variables don't consider partial stability which would easily lead to spurious regression. For the decomposition of energy intensity, most scholars decompose total energy intensity into the structural factors caused by changes in industrial structure and efficiency factors caused by changes in the industrial sector's energy efficiency. However, this method does not consider the household energy consumption which accounts for about $11 \%$ of the total energy consumption. For DEA approach, most researchers do not put into consideration of environmental indicators. Even though some individuals consider environmental factors in the DEA model, but they only add contamination index into input indicators and DEA model don't support too many input indicators. Total factor energy efficiency is relatively focused on comparison of energy efficiency in all regions of China, which is lack of research in deep-seated reasons for the impact of energy efficiency. By controlling the energy consumption per unit GDP, researches focused on the achievement of qualitative theory and quantitative research is not too much. These fields which Chinese scholars now research defectively in energy efficiency are good directions for future research.

\section{References}

[1] Afriat $\mathrm{S} \mathrm{N}$. Efficiency estimation of production functions [J]. International Economic Review, 1972, 13(3): 568-598.

[2] Bian, Y., \& Yang, F. (2010). Resource and environment efficiency analysis of provinces in China: A DEA approach based on Shannon's entropy. Energy Policy, 38(4), 1909-1917.

[3] Boles J N. Efficiency squared-efficient computation of efficiency indexes [C]. In Proceedings of the 39' $t$ ' Meeting of the western Farm Economic Association, 1966, 137-142.

[4] Boyd, G. A., \& Pang, J. X. (2000). Estimating the linkage between energy efficiency and productivity. Energy policy, 28(5), 289-296.

[5] Cao, S., Xie, G., \& Zhen, L. (2010). Total embodied energy requirements and its decomposition in China's agricultural sector. Ecological Economics, 69(7), 1396-1404.

[6] Chang, T. P., \& Hu, J. L. (2010). Total-factor energy productivity growth, technical progress, and efficiency change: An empirical study of China. Applied Energy, 87(10), 3262-3270.

[7] Charnes A, Cooper W W, Rhodes E. Measuring the efficiency of decision-making units [J].European Journal of operational Research, 1978, 3(4): 339-338.

[8] Crompton, P., \& Wu, Y. (2005). Energy consumption in China: past trends and future directions. Energy economics, 27(1), 195-208.

[9] Banker R D, Charnes A, Cooper W W. Some models for estimating technical and scale inefficiencies in data envelopment analysis [J]. Management Science, 1984, 30: 1078-1092.

[10] Fan, Y., Liu, L.-C., Wu, G., Wei, Y.-M., 2007. Changes in carbon intensity in China: Empirical findings from 1980-2003. Ecological Economics 62, 683-691.

[11] Färe, R., Grosskopf, S., \& Hernandez-Sancho, F. (2004). Environmental performance: an index number approach. Resource and Energy economics, 26(4), 343-352. 
[12] Fisher-Vanden, K., Jefferson, G. H., Liu, H., \& Tao, Q. (2004). What is driving China's decline in energy intensity?. Resource and Energy Economics, 26(1), 77-97.

[13] Freeman, S. L., Niefer, M. J., \& Roop, J. M. (1997). Measuring industrial energy intensity: practical issues and problems. Energy policy, 25(7), 703-714.

[14] Hu J L, Kao C H. Efficient energy-saving targets for APEC economies [J]. Energy Policy, 2007,35(1): 373-382.

[15] Hu, J. L., \& Wang, S. C. (2006). Total-factor energy efficiency of regions in China. Energy policy, 34(17), 3206-3217.

[16] Kambara, T. (1992). The energy situation in China. The China Quarterly, 131, 608-636.

[17] Kong, X., Lu, S., \& Wu, Y. (2012). A review of building energy efficiency in China during "Eleventh Five-Year Plan" period. Energy policy, 41, 624-635.

[18] Mukherjee, K. (2008). Energy use efficiency in the Indian manufacturing sector: an interstate analysis. Energy Policy, 36(2), 662-672.

[19] Yang, M. (2008). China's energy efficiency target 2010. Energy Policy, 36(2), 561-570.

[20] Price, L., Levine, M. D., Zhou, N., Fridley, D., Aden, N., Lu, H. \& Yowargana, P. (2011). Assessment of China's energy-saving and emission-reduction accomplishments and opportunities during the 11th Five Year Plan. Energy Policy, 39(4), 2165-2178.

[21] Shi, G. M., Bi, J., \& Wang, J. N. (2010). Chinese regional industrial energy efficiency evaluation based on a DEA model of fixing non-energy inputs. Energy Policy, 38(10), 6172-6179.

[22] Wing, I. S. (2008). Explaining the declining energy intensity of the US economy. Resource and Energy Economics, 30(1), 21-49.

[23] Yeh, T. L., Chen, T. Y., \& Lai, P. Y. (2010). A comparative study of energy utilization efficiency between Taiwan and China. Energy policy, 38(5), 2386-2394.

[24] Zhang, Z. (2003). Why did the energy intensity fall in China's industrial sector in the 1990s? The relative importance of structural change and intensity change. Energy Economics, 25(6), 625-638.

[25] Zhang, Y. (2009). Structural decomposition analysis of sources of decarbonizing economic development in China; 1992-2006. Ecological Economics, 68(8), 2399-2405.

[26] Zhang, J., \& Wang, G. (2008). Energy saving technologies and productive efficiency in the Chinese iron and steel sector. Energy, 33(4), 525-537.

[27] Zheng, J., Liu, X., \& Bigsten, A. (2003). Efficiency, technical progress, and best practice in Chinese state enterprises (1980-1994). Journal of Comparative Economics, 31(1), 134-152. 